\title{
The Thermal Polymerization of Orosomucoid
}

\author{
By S. P. SPRAGG AND H. B. HALSALL \\ Department of Chemistry, University of Birmingham \\ AND T. H. FLEWETT AND GRIZEL R. BARCLAY \\ Regional Virus Laboratory, East Birmingham Hospital, Birmingham
}

(Received 24 June 1968)

\begin{abstract}
1. Orosomucoid was prepared from the urine of a nephrotic patient and polymerized by heating it in a range of salt concentrations at pH4.1. 2. Heating at low ionic strengths produced a 'chain' polymer of indefinite length but having the same width as the diameter of the monomer (5.0 nm.). Similar treatment in high ionic strengths also produced a spherical ('ball') polymer of limited diameter (14.8nm.). 3. The size and shape of both polymers were determined from ultracentrifuge, gel-filtration and electron-microscope results. The results suggest that eight monomer units condense to form the ball polymer. 4. Heating orosomucoid at pH 1.8 hydrolysed the $N$-acetylneuraminic acid off the molecule; only chains could then be formed, even in high ionic strengths. 5. Both polymers were stable under normal conditions but could be depolymerized in $3 \mathrm{M}$-guanidine hydrochloride. The monomer could be repolymerized on heating: the 'chain monomer' only formed chains at all ionic strengths, but the 'ball monomer' was indistinguishable from the original monomer in its immunological properties and polymerization reaction.
\end{abstract}

The $\alpha_{1}$-globulin, orosomucoid, is a glycoprotein containing $10-14 \%$ of $N$-acetylneuraminic acid. In common with many other glycoproteins orosomucoid can inhibit the reaction between the influenza virus and the erythrocyte membrane, provided that the orosomucoid solution is first polymerized by heating (Tyrrell, 1954). The active unit was found to be a polymer of orosomucoid; the monomer showed marginal biological activity (Whitehead, 1965; Whitehead, Flewett, Foster \& Sammons, 1965; Morawiecki \& Lisowska, 1965; Lobodzinska, Morawiecki, Zielinska \& Skurska, 1966). The polymerization involves no apparent degradation of the monomer, and the resulting polymer is highly soluble in various aqueous solvents.

Little is known about the polymerization reaction or the marked change in biological activity accompanying it. However, the increase in activity with size seems to be in accord with the requirements postulated by Fazekas de St Groth \& Gottschalk (1963) for haemagglutination inhibition.

At the start of the present work, it was hoped that precise results on the virus-polymer reaction could be obtained, but it soon became apparent that the polymerization reaction was more complex than was at first described (Whitehead, 1965). We therefore further examined this reaction. The results are presented in this paper.
Two types of polymer were produced by heating orosomucoid in sodium chloride media: spherical ('ball'), or filamentous ('chain'), or a mixture of both shapes; the factor determining the polymer shape was the ionic strength of the heated solution. The depolymerization of both polymers with guanidine hydrochloride solutions showed that the intermolecular bonds of the polymers were not covalent. The relationship between molecular shape and activity of the polymers is discussed in the next paper (Barclay, Flewett, Keller, Halsall \& Spragg, 1969).

\section{MATERIALS AND METHODS}

Orosomucoid. Orosomucoid was extracted from the urine of a single patient with the nephrotic syndrome, by a modification of the method of Barker \& Whitehead (1963). Urine (301. or more) was dialysed against sodium acetateacetic acid buffer, $\mathrm{pH} 4.9\left(0.02 \mathrm{M}-\mathrm{Na}{ }^{+}\right)$, for $24 \mathrm{hr}$. at $4^{\circ}$, and filtered on a sintered-glass pad under gentle suction. The urine was applied to a column $(50 \mathrm{~cm} . \times 7 \mathrm{~cm}$.) of DEAEcellulose (Whatman Chromedia DE 11) equilibrated with the same acetate buffer. The DEAE-cellulose was prepared for use by stirring it in $0.5 \mathrm{M}-\mathrm{NaOH}(10 \mathrm{~g}$. of DEAEcellulose/l.) for $24 \mathrm{hr}$., washing it copiously with water and stirring it in $0.5 \mathrm{M}-\mathrm{NaCl}$ for $12 \mathrm{hr}$. The resin was then stirred overnight in the acetate buffer before being packed. After the packing, the column was washed with 3 column volumes of the buffer at the flow rate to be used for the fractionation, normally the natural flow rate of the column. After 
application of the urine, the column was eluted stepwise with 21. each of acetate buffers, pH4.5 (0.04 M-Na+), pH4.3 $\left(0.05 \mathrm{M}-\mathrm{Na}^{+}\right)$, and $\mathrm{pH} 4.0\left(0.10 \mathrm{M}-\mathrm{Na}{ }^{+}\right), 250 \mathrm{ml}$. fractions being collected. The fractions in acetate buffer, $\mathrm{pH} 4 \cdot 0$ $\left(0 \cdot 10 \mathrm{M}-\mathrm{Na}^{+}\right)$, were scanned by the Warren (1959) assay for sialic acid, and those containing a significant proportion of sialic acid were pooled, dialysed for $48 \mathrm{hr}$. against water at $4^{\circ}$ and freeze-dried. The product was stored at $-10^{\circ}$. Final purification of the crude orosomucoid was by fractionation on Sephadex G-75 equilibrated and run in acetate buffer, pH4.9 $\left(0.02 \mathrm{~m}-\mathrm{Na}^{+}\right)$. The dimensions of the column were $122 \mathrm{~cm} . \times 3 \mathrm{~cm}$. and the flow rate was $8.5 \mathrm{ml} . / \mathrm{cm} \cdot{ }^{2} / \mathrm{hr}$. Sample loads were up to $2 \mathrm{~g}$.

Antisera. Whole human antiserum and a specific orosomucoid antiserum were kindly provided by Dr G. I. Pardoe (Rheumatism Research Wing, Queen Elizabeth Hospital, Birmingham), who also carried out the immunoelectrophoretic analyses.

Materials for gel-column calibration. These were used without further purification: horse myoglobin from Seravac Laboratories Pty. Ltd. (Maidenhead, Berks.); ovalbumin (lot A102B-250) from Sigma Chemical Co. (St Louis, Mo., U.S.A.); turnip-yellow-mosaic virus supplied by $\mathrm{Mr}$ R. F. Goodman, Department of Chemistry, University of Birmingham; bovine serum albumin supplied by Mr R. P. Stokes, Rheumatism Research Wing, Queen Elizabeth Hospital, Birmingham; 7s $\gamma$-globulin (lot Rd038) from AB Kabi (Stockholm, Sweden); human $\alpha_{2}$-macroglobulin supplied by Dr D. Normansell, Rheumatism Research Wing, Queen Elizabeth Hospital, Birmingham.

Guanidine hydrochloride. This was biochemical grade, obtained from British Drug Houses Ltd. (Poole, Dorset), and was recrystallized before use.

Sedimentation analyses. These were performed at $20^{\circ}$ in a Spinco model $\mathbf{E}$ analytical ultracentrifuge fitted with an RTIC unit, with $0 \cdot 1 \mathrm{M}-\mathrm{NaCl}$ solution as the solvent. The speed used was generally $59780 \mathrm{rev} . / \mathrm{min}$., though a few runs were carried out at $50740 \mathrm{rev} . / \mathrm{min}$. Sedimentation coefficients, corrected for solvent viscosity and density, i.e. $S_{\mathbf{2 0} \text {, w }}$, were calculated from the measured ordinates by a least-squares routine to fit the results to a straight line and so obtain an estimate of the internal standard errors. In general the coefficient of variation for all the constants was approx. $\pm 1 \%$ of the given value. The number of measurements used in the fitting was not less than four and generally about six.

Tests for the inhibition of viral haemagglutination. Experimental details of these tests are given in the next paper (Barclay et al. 1969).

Electron microscopy. Solutions of orosomucoid in various concentrations, usually about $0.5 \mathrm{~g} . / 100 \mathrm{ml}$., were mixed with an equal volume of $2 \%(w / v)$ potassium phosphotungstate, $\mathrm{pH} 7 \cdot 0,2 \%(\mathrm{w} / \mathrm{v})$ potassium borotungstate, $\mathrm{pH} 7 \cdot 0$, or uranyl formate, $\mathrm{pH}$ about 4.5 , prepared by the method of Finch (cited by Bradley, 1965). A small drop of the mixture was touched to the surface of a grid bearing a carbon membrane, and the excess was removed by blotting. When dry, the grids were examined in a Philips EM 200 electron microscope with an $80 \mathrm{kv}$ electron beam focused to a spot size of about $2 \mu$. A cold-trap to prevent contamination of the specimens was found valuable. Micrographs were made at a magnification of 50000 on film and further enlarged tenfold to give a final magnification of 500000 .
To find the concentration of polymer that would allow isolated molecules to be recorded, serial dilutions of polymer were mixed with negative stain. Polymer molecules were most easily detected when uranyl formate was used as the negative stain, and borotungstate was found to be better than phosphotungstate. To detect polymer molecules attached to influenza-virus particles, phosphotungstate gave the clearest pictures of both virus and polymer together; borotungstate did not clearly delineate influenzavirus spikes (Flewett \& Apostolov, 1967).

Gel filtration. (a) Preparation of gels. The $2 \%$ agarose (a gift from Dr N. M. Young, St Luke's Hospital, Cleveland, Ohio, U.S.A.) was already in the swollen state. Sephadex G.75 and G-150 were swollen in dilute $\mathrm{KCl}$ solution (Andrews, 1965) at $4^{\circ}$ for at least 14 days before use, and for considerably longer if possible. All gels were refined by decantation and resuspension, and then degassed under reduced pressure before use.

(b) Preparation and use of columns. The gel columns were prepared in the normal manner, by equilibrating them with at least 3 column volumes of solvent before use. All samples were applied to columns by carefully layering the solution, made denser by the addition of $\mathrm{NaCl}$ or sucrose, on top of the gel surface in the presence of the eluting solvent. Effluents were collected on a fraction collector by using time-drop or drop-count systems (LKB-Produkter AB, Stockholm, Sweden) or by siphoned fractions.

Polymerization. A $\mathbf{0 . 5 \%}$ solution of orosomucoid was prepared by dissolving the freeze-dried sodium salt in the appropriate solvent in a stoppered test tube. It was

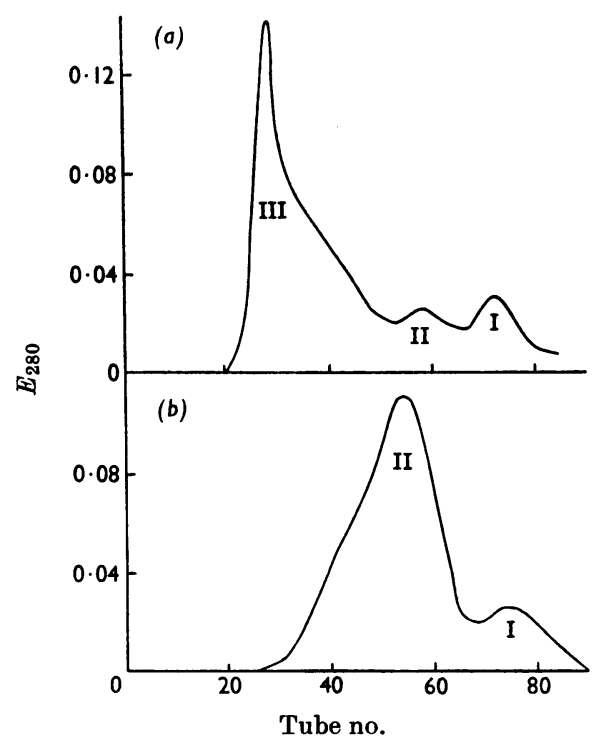

Fig. 1. Elution patterns for polymerized orosomucoid after it had been heated at $80^{\circ}$ for $1 \mathrm{hr}$. in $(a) 0.19 \mathrm{M}-\mathrm{NaCl}$ and (b) $1.1 \mathrm{M}-\mathrm{NaCl}$. Samples were applied to a column of Sephadex G-150 and the effluent was run immediately into a column of $2 \%$ agarose beads. The eluent was $0 \cdot 1 \mathrm{~m}-\mathrm{NaCl}$. I, Monomer; II, ball polymer; III, chain polymer. 
partially immersed in a water bath at the temperature of polymerization. The variation of temperature about the polymerization temperature was approx. $\pm 0.2^{\circ}$. After being heated for a set time (see the Results section), the tube and contents were cooled for about $5 \mathrm{~min}$. in cold water. The $\mathrm{pH}$ of the medium was always $4 \cdot 1$ except when the effect of $\mathrm{pH}$ on the reaction was being examined. Raising the temperature from $25^{\circ}$ to $80^{\circ}$ raised the $\mathrm{pH}$ of the solution by approx. $0 \cdot 1 \mathrm{pH}$ unit.

Separation of polymerization products. Two cascaded columns were used, one $(49 \mathrm{~cm} . \times 2 \mathrm{~cm}$.) of Sephadex G-150, the other $(51 \mathrm{~cm} . \times 3 \mathrm{~cm}$.) of $2 \%$ agarose beads. The outlet of the Sephadex G-150 column was connected via Tygon tubing to the inlet of the agarose column. Samples were run on this apparatus in $0.1 \mathrm{M}-\mathrm{NaCl}$ and at $4^{\circ}$ at a flow rate of $2.4 \mathrm{ml} . / \mathrm{cm} .{ }^{2} / \mathrm{hr}$., the areas of the gel surfaces being considered additive. Fig. 1 shows typical elution diagrams for the chromatography of two samples of polymerized orosomucoid. With the cascade system it is possible to separate molecules of widely differing molecular sizes in one experiment.

Treatment with guanidine hydrochloride. The solution being examined was dialysed against the guanidine hydrochloride solution for $48 \mathrm{hr}$. before examination.

\section{RESULTS}

Homogeneity of the monomeric orosomucoid preparation. The method of preparation gave material that yielded a single peak when examined by both gel filtration on a column $(122 \mathrm{~cm} . \times 3 \mathrm{~cm}$.) of Sephadex G-75 (sample load 100mg.) and by sedimentation analysis of a $1 \%(\mathrm{w} / \mathrm{v})$ solution at $59780 \mathrm{rev} . / \mathrm{min}$., which gave $S_{20 . \mathrm{w}}^{1 \%} 2 \cdot 72 \mathrm{~s}$ (Fig. 2). Immunoelectrophoresis in barbitone buffer, pH 8.6 and $I 0.05$, for $3 \mathrm{hr}$. at $15 \mathrm{~mA}$ against whole human antiserum gave a single precipitin line. The original method (Whitehead, 1965) yielded an impure preparation as defined by these tests.

Effect of the salt concentration, heating time and temperature on polymerization. It was found that heating orosomucoid in $1 \%(\mathrm{w} / \mathrm{v})$ sodium chloride solution produced a mixture of two distinct polymer types, a filamentous ('chain') and a spherical

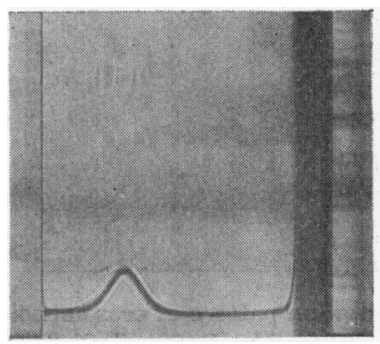

Fig. 2. Sedimentation pattern of purified orosomucoid after $101 \mathrm{~min}$. in a Spinco model $\mathbf{E}$ analytical ultracentrifuge at $59780 \mathrm{rev} . / \mathrm{min}$. $\left(\omega^{2} t=2.37 \times 10^{11} \mathrm{sec}\right.$. $)$; the schlieren bar angle was $55^{\circ}$. ('ball') polymer. These were recognized by measuring the $S_{20 \text {,w }}$ values of the two boundaries formed in the analytical ultracentrifuge and later correlating the results with the shapes seen in electron micrographs (see below). When the monomer was heated at $80^{\circ}$ for $1 \mathrm{hr}$. in water or sodium chloride solution (up to $12 \%, w / v$ ), the chain had $S_{20, w} 30$ s and the ball had $S_{20, w}$ approx. 12s. It was found that the chain formation was favoured by low salt concentration, with no detectable ball formation in water, whereas the ball was formed in higher salt solutions (Fig. 3 and Table 1 ). The results given in Table 1 show the progressive increase in ball polymer produced at the expense of the chain polymer as the salt concentration in the reaction mixture was increased. The results from this and other experiments suggest that the efficiency of the polymerization increased at relatively high salt concentrations. Qualitative

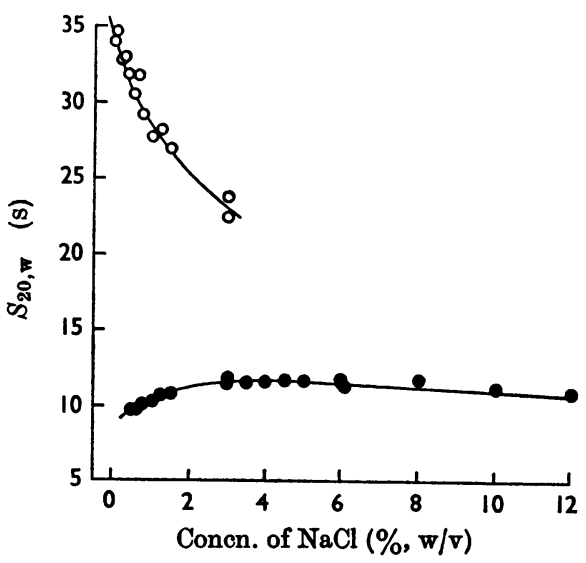

Fig. 3. Relationship between $S_{20 \text {,w }}$ and $\mathrm{NaCl}$ concentration of the medium after orosomucoid had been heated for $1 \mathrm{hr}$. at $80^{\circ}$. O, Chain polymer; $\bullet$, ball polymer.

Table 1. Estimates of the relative quantities of the two polymers formed after orosomucoid had been heated at $80^{\circ}$ for $1 \mathrm{hr}$. at various concentrations of sodium chloride

The estimates were made by integrating the areas under the respective peaks from elution patterns similar to those given in Fig. 1 .

Concn. of $\mathrm{NaCl}$ $(\%, w / v)$

$1 \cdot 0$

3.0

$6 \cdot 0$

8.0

\begin{tabular}{ccc}
\multicolumn{3}{c}{ Percentages } \\
Monomer & Ball & Chain \\
16 & 12 & 72 \\
14 & 42 & 44 \\
15 & 85 & 0 \\
0 & 100 & 0
\end{tabular}


results from ultracentrifuge experiments showed a similar dependence of polymerization on the salt concentration; in this case, however, it was not possible to make meaningful measurements from the patterns.

Although $S_{20, w}$ of the chain polymer decreased with increasing salt concentration, it is impossible from these results to say that increasing the sodium chloride concentration decreases the weightaverage chain sizes. The decrease in $S_{20, w}$ could result from an increased viscosity plus JohnstonOgston effects (Johnston \& Ogston, 1946) on the sedimentation of the chain polymers due to increased ball concentrations. It seems probable, however, that the initial increase in $S_{20, w}$ of the ball polymer with increasing salt concentration reflects an increase in the weight-average size of the ball polymer. The decrease in $S_{20, w}$ at higher salt concentrations could be explained by normal hydrodynamic concentration effects on the boundary velocity, though we have not so far been able to estimate this effect. The $S_{\mathbf{2 0} \text {,w }}$ for the ball reached a limiting value of approx. $12.5 \mathrm{~s}$ in $6 \%(\mathrm{w} / \mathrm{v})$ sodium chloride solution. The highest $S_{20 \text {,w }}$ value for the chain $(35 \mathrm{~s})$ was found with water as the solvent.

The heating times and temperatures used in the above experiments were first determined by running a series of tests in which either the time of heating or the temperature was varied at constant salt and monomer content. Increasing the reaction temperature at a constant heating time of $1 \mathrm{hr}$. in $1 \%(\mathrm{w} / \mathrm{v})$ sodium chloride favoured larger chain sizes but gave a virtually constant size for the ball polymer (Fig. 4). An essentially similar result was obtained with $6 \%(\mathrm{w} / \mathrm{v})$ sodium chloride instead of $1 \%(\mathrm{w} / \mathrm{v})$ sodium chloride. When the time of heating at $80^{\circ}$ in $1 \%(\mathrm{w} / \mathrm{v})$ sodium chloride was progressively increased, larger chain sizes were again observed, the size of the ball polymer remain-

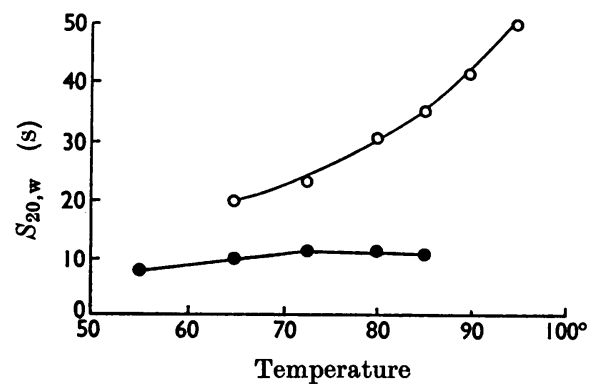

Fig. 4. Relationship between $\boldsymbol{S}_{20 \text {,w }}$ and incubation temperature after orosomucoid had been heated for $1 \mathrm{hr}$. in $1 \% \mathrm{NaCl}$ solution. $O$, Chain polymer; $\bullet$, ball polymer. ing constant. Since heating at $80^{\circ}$ for $1 \mathrm{hr}$. was a convenient experimental procedure and the results were repeatable, this method was used as a routine to prepare batches of polymer.

Effect of $\mathrm{pH}$ on polymerization. A solution of the sodium salt of orosomucoid in either water or aqueous sodium chloride had $\mathrm{pH} 4 \cdot 1$, and the above results were obtained at this value. Orosomucoid, however, has an isoelectric point between $\mathrm{pH} 1 \cdot 0$ and 3.0 (Schmid, 1953; Weimer, Mehl \& Winzler, 1950) and hence the monomer has an excess of negative charge at $\mathbf{p H} 4 \cdot 1$. An attempt was made to test whether the neutral molecule could be polymerized. The $\mathrm{pH}$ of a solution of orosomucoid in either water or $1 \%$ sodium chloride was adjusted to 1.8 with $\mathrm{N}$-hydrochloric acid and then heated at $80^{\circ}$ for $1 \mathrm{hr}$. No polymerization was detected in acid alone, but chain polymers were produced when $6 \%(\mathrm{w} / \mathrm{v})$ sodium chloride was used with the acid; these had $S_{20, w}$ approx. 34s. It was found that at $\mathrm{pH} 1 \cdot 8$ all the $N$-acetylneuraminic acid was hydrolysed off the orosomucoid during the polymerization reaction.

Effect of other solvents on polymerization. The presence of $0.3 \mathrm{M}$-guanidine hydrochloride or traces of acetate (not more than $0.032 \mathrm{M}$ at $\mathrm{pH} 4.9$ ) completely prevented polymerization. Polymerization in $1 \%$ ethanol or $0.05 \%$ sodium dodecyl sulphate produced a heterogeneous mixture of polymers of intermediate size and shape.

It was found that replacing $\mathrm{Na}^{+}$or $\mathrm{Cl}^{-}$with $\mathrm{K}^{+}$ or $\mathrm{NO}_{3}{ }^{-}$at equivalent ionic strengths did not significantly affect the polymerization.

Reversing the polymerization. The polymers produced in all the reactions appeared to be stable and showed no signs of reverting to monomer on being kept for several weeks, or on extensive dialysis against $6 \%(\mathrm{w} / \mathrm{v})$ sodium chloride, at $4^{\circ}$. However, adding guanidine hydrochloride until the final concentration reached $2 \mathrm{M}$ completely depoly-

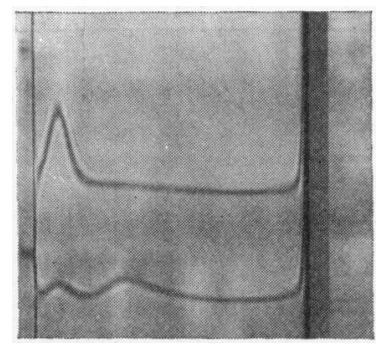

Fig. 5. Sedimentation pattern of orosomucoid after it had been heated at $80^{\circ}$ for $1 \mathrm{hr}$. in $6 \% \mathrm{NaCl}$ (bottom), and the solution had then been treated with $6 \mathrm{M}$-guanidine hydrochloride (top). The picture was taken after $32 \mathrm{~min}$. in a Spinco model $E$ analytical ultracentrifuge at $59780 \mathrm{rev} . /$ min. $\left(\omega^{2} t=7 \cdot 51 \times 10^{10}\right.$ sec. $)$; the schlieren bar angle was $60^{\circ}$. 


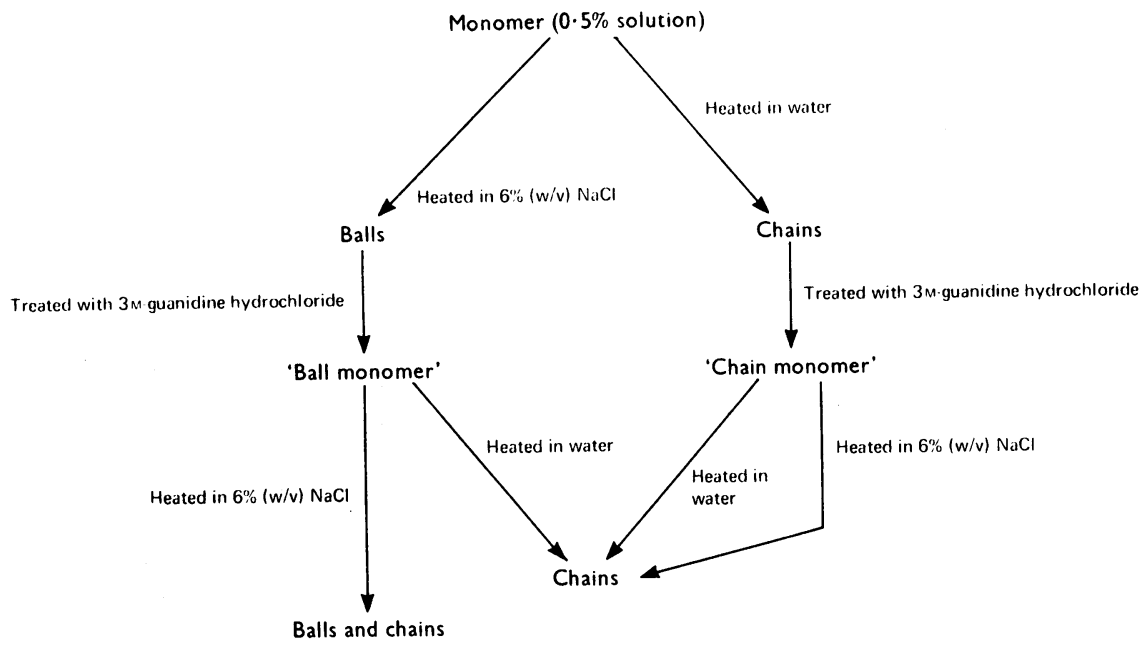

Scheme 1. Sequence of experiments carried out with guanidine hydrochloride on the orosomucoid polymers.

merized the ball polymer in $48 \mathrm{hr}$. A longer period was needed for the chain polymer to be completely depolymerized at this guanidine concentration, but $48 \mathrm{hr}$. sufficed if $3 \mathrm{M}$-guanidine was used. The resulting monomer had $S_{20, w} 2 \cdot 8 \mathrm{~s}$ and appeared to have the same sedimentation and immunological properties as the starting monomer (Fig. 5 shows the sedimentation pattern before and after treatment). After the depolymerization, the monomer solution had to be dialysed against $6 \%(\mathrm{w} / \mathrm{v})$ sodium chloride for $48 \mathrm{hr}$. and then against several changes of water for $72 \mathrm{hr}$. at $4^{\circ}$ before the monomer could be repolymerized by heating.

The discovery that the polymer could be reversibly depolymerized readily led to the series of experiments shown in Scheme 1. The two monomer solutions produced by the $48 \mathrm{hr}$. $3 \mathrm{M}$ guanidine treatment of both the ball and the chain polymer solutions were divided into two portions after dialysis. These solutions were reheated in either water or $6 \%$ sodium chloride for $1 \mathrm{hr}$. at $80^{\circ}$ and then examined in the ultracentrifuge. It was found that the 'ball monomer' heated in $6 \%$ $(w / v)$ sodium chloride produced a mixture of ball and chain polymers, but when water was used only chain polymer was produced. With 'chain monomer', only chains could be formed even when $6 \%(w / v)$ sodium chloride was used as the solvent.

In these experiments the original monomer solution was divided into three portions; one was used in the polymerization experiments described above, and the other two were treated as controls. Of the controls, one was dialysed against $6 \%(\mathrm{w} / \mathrm{v})$ sodium chloride and the other was dialysed against 3 m-guanidine hydrochloride, both for $48 \mathrm{hr}$. The sodium chloride control showed the normal polymerization reactions described previously. So did the guanidine hydrochloride control after extensive dialysis against $6 \%(\mathrm{w} / \mathrm{v})$ sodium chloride (approx. 7 days at $4^{\circ}$ ); dialysis against water was not sufficient to remove the guanidine from the orosomucoid.

Treatment of either polymer with $0 \cdot 1 \mathrm{M}$-sodium acetate solution, $\mathrm{pH} 4 \cdot 0$, did not have any significant effect on molecular size and shape.

Interconversion of the polymers. The possibility that the chains were an intermediate in the formation of the balls or vice versa was tested by first preparing the polymers with either water or $6 \%$ (w/v) sodium chloride as the reaction solvent. The solutions were then treated by first dialysing each polymer solution against the other solvent at $4^{\circ}$ and then reheating at $80^{\circ}$ for $1 \mathrm{hr}$. The results showed that the $S_{20, w}$ of the ball increased from approx. 12s before to $35 \mathrm{~s}$ after reheating, but the $S_{20, w}$ of the chain remained constant at approx. $35 \mathrm{~s}$ despite the reheating in sodium chloride solution. This showed that the ball polymer can form a chain but not the reverse.

Size and shape of the polymers determined by gel filtration and from electron micrographs. The sedimentation velocities suggested that the polymers were of considerable size, and preparations containing both types [i.e. with $1 \%(w / v)$ sodium chloride as the polymerizing solvent] were examined in the electron microscope. The two types could be distinctly recognized (see Plates $1 a, 1 b$ and $2 c$ in Barclay et al. 1969). It was possible to measure some of the molecular co-ordinates from pictures similar to these. 


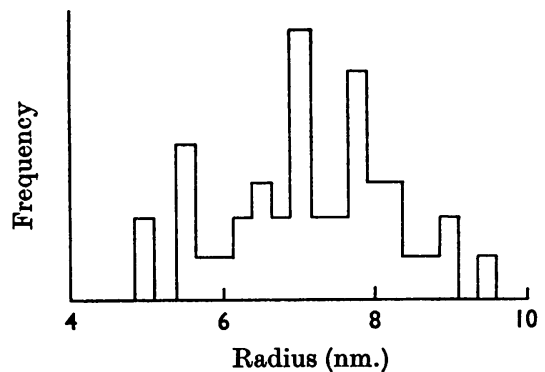

Fig. 6. Frequency histogram of the radii of ball polymers observed from electron micrographs.

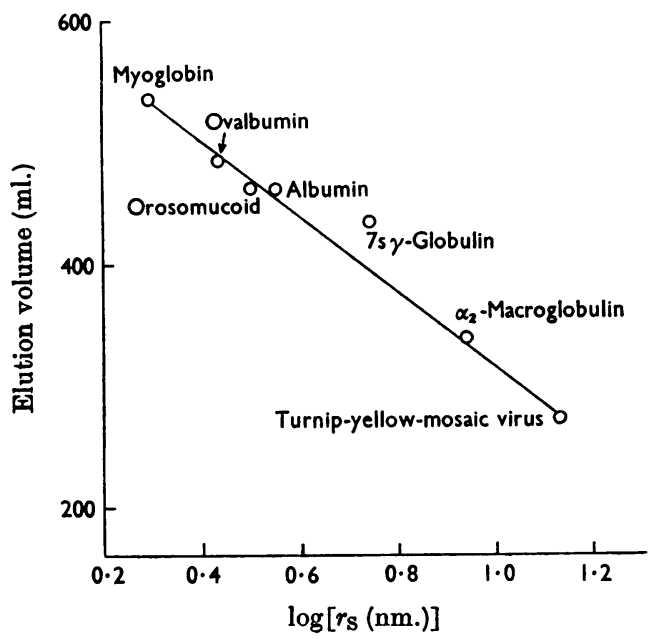

Fig. 7. Relationship between the elution volume and $\log r_{\mathrm{S}}$ ( $r_{\mathrm{S}}$ Stokes radius) on a Sephadex G-150 column followed by a $2 \%$ agarose-bead column (see Fig. 1).

The mean width of the chain molecules was approx. 5.0 nm. but it was impossible to determine their length owing to intertwining of the chains. A more exact analysis of molecular dimensions could be made with the balls; their mean radius was found to be $7 \cdot 4 \mathrm{~nm}$. The spread was surprisingly small, as seen in the frequency diagram (Fig. 6). Naturally the spectrum of sizes that can be seen in the electron microscope is limited by the resolving power of the negative-staining technique used, probably no better than $1.5 \mathrm{~nm}$., perhaps no better than $2 \cdot 0 \mathrm{~nm}$. (Valentine \& Horne, 1962), and hence the resulting number-average size may be weighted towards the larger molecules. This truncation of the distribution in one direction may account for the observed distribution not appearing as a normal distribution. It should be mentioned, however, that no balls were observed having a radius greater than $10.0 \mathrm{~nm}$. As a first approximation one can take the mean average radius to be $7 \cdot 4 \mathrm{~nm}$. It was decided to compare these results with the weightaverage Stokes radius $\left(r_{\mathbf{S}}\right)$ determined from gel filtration (Hjertén, 1964; Andrews, 1965). To do this it was necessary to choose a gel that separates the components in the polymer mixture so that the elution volumes of the polymers could be assessed. These were then compared with elution volumes of well-described macromolecules on the same gel columns. Tests showed that a $2 \%$ agarose-bead column fulfilled the present requirements since the chain polymer was eluted in the void volume (i.e. was completely excluded from the gel), whereas the ball polymer was retained. However, the orosomucoid monomer and the ball polymer were not resolved by this gel, but these could be resolved on Sephadex G-150, so the agarose and the Sephadex columns were cascaded, with the effluent from the Sephadex G-150 going through the agarose column before collection. The calibration curve of $\log r_{\mathrm{S}}$ versus elution volume (Fig. 7) for the combined columns gave the expected straight line (Andrews, 1965). From this line it was found that the ball had a limiting radius value of $7 \cdot 4 \mathrm{~nm}$.

\section{DISCUSSION}

Both the shape and the size of the orosomucoid polymer are relevant to its biological activity. The following paper (Barclay et al. 1969) provides evidence that the chain polymer actively inhibits influenza-virus haemagglutinin, whereas the ball polymer does not. This clear-cut difference in activities makes it important to discuss the results in the present study with particular reference to the construction of the polymers.

The first aspect of interest was the ease with which dilute salt solutions could influence the aggregation. In solutions of low ionic strength there forms a long-chain polymer, of indefinite length but of uniform width. This width appears to correspond to the monomer diameter, approx. 5.0nm., calculated from the molecular weight of 40000 (Schultze, Gollner, Heide, Schonenberger \& Schwick, 1955) and density $1.42 \mathrm{~g} . / \mathrm{ml}$. (Smith, Brown, Weimer \& Winzler, 1950), assuming the monomer to be a sphere. Hence the monomer reacts as though it were polarized, having two sites/ molecule separated by the diameter of the molecule.

In contrast with the chain, the ball apparently has a limiting radius that is not greater than $10 \mathrm{~nm}$. and has an average value of approx. $7 \cdot 4 \mathrm{~nm}$. The correlation between the electron-microscope and the gel-filtration results was surprisingly good for this estimate, considering the possible limits in the electron-microscope estimates. If one accepted this 
value as a first-order estimate, it was found that 8.5 monomers could pack around a hollow sphere of diameter $14.8 \mathrm{~nm}$. A similar estimate was obtained by taking $S_{20, w} 12 \mathrm{~s}$ for the ball and $3 \mathrm{~s}$ for the monomer: then the approximate molecular weight of the ball would be 320000 ; in other words eight monomer units form the ball.

The packing of a monomer into the ball suggests that four potential sites exist on the monomer and these are situated approx. $90^{\circ}$ apart. This state is stable when the monomer is heated in salt, but the four sites are decreased to two by either heating the monomer in solutions of low ionic strength or removing the carbohydrate by hydrolysis at $\mathrm{pH} 1 \cdot 8$. These two conditions produce chain polymers and, since the ball polymer can be converted into a chain by heating it in low ionic strength, but not the reverse, the state of the monomer in the chain polymer is irreversibly changed from the state in the ball polymer. The results of the guanidine depolymerization suggest that any rearrangements that may occur during the formation of a ball polymer are reversible, since the depolymerized ball monomer can re-form balls or chains; however, the formation of the chain is accompanied by irreversible rearrangements of the monomer that prevent subsequent ball formation from the chain monomers.

In an examination of the polymerization reaction, Whitehead \& Winzler (1968) reported the formation of biologically active polymers when orosomucoid was heated in approx. $1 \%(\mathrm{w} / \mathrm{v})$ sodium chloride solutions. These polymers had sedimentation properties similar to those found for the chain polymer. The biological activity was lost when these polymers were treated with $8 \mathrm{M}$-urea solution, and it seems probable that this treatment depolymerized the polymer in a similar way to that found with guanidine hydrochloride. The results from this parallel study generally support the present work; however, they differ in the effect of acetate on the polymerization. Whitehead \& Winzler (1968) heated orosomucoid in acetatebarbiturate buffers and found maximal polymer production at $\mathrm{pH} 3 \cdot 8$, whereas results in the present work showed that traces of acetate inhibited the polymerization. Further work on the influence of acetate mixtures on the polymerization reaction is necessary before this anomaly can be explained.

The polymerization takes place under non-ideal conditions for aggregation as far as the net charge of the molecule is concerned, i.e. the monomer at pH4.1 is strongly negatively charged and at pH 1.8 the protein without $N$-acetylneuraminic acid has a strong positive charge (Popence \& Drew, 1957). It seems therefore that the excess of charge cannot be uniformly distributed over the molecule but is locally situated, and the monomers can approach one another without great hindrance by charge repulsion.

Previous optical-rotatory work by Schmid \& Kamiyama (1963) showed that large structural changes occur when orosomucoid is mixed with guanidine hydrochloride; this is consistent with data from other proteins, which show that proteins reversibly form random coils with this reagent (Tanford, Kawahara \& Lapanje, 1966). These changes may cause the depolymerization by this reagent. It is relevant when one is considering the effect of heating on the monomer to note that the guanidine results demonstrate that covalent bonds are not formed between the monomers during polymerization. In other words the bonding is by either hydrogen bonds or electrostatic attraction between the monomers.

The controlled formation of two types of polymer from a single monomer, of which only one interacts with the influenza virus (Barclay et al. 1969), should make it possible to define more closely the molecular properties responsible for the polymer-virus interaction. The present work had a limited objective, namely the study of the polymerization of orosomucoid when heated and the relation of the results to the subsequent reaction of the polymer with the influenza virus. This study has been partially achieved, although the results obtained are essentially qualitative. It will now be possible to make a more detailed comparative study of the properties of the two polymers, which may yield information directly related to the desirable molecular properties for biological effects.

The authors thank Dr G. A. Gilbert for helpful discussion throughout this work. The work presented in this paper forms part of a Thesis presented by H.B.H. to Birmingham University for the degree of $\mathrm{Ph} . \mathrm{D}$., and H.B.H. thanks the University of Birmingham for a maintainence grant from its Appeal Fund. Extra thanks are also given to Dr P. H. Whitehead for allowing us to have a pre-publication copy of his paper with Dr R. J. Winzler (Whitehead \& Winzler, 1968).

\section{REFERENCES}

Andrews, P. (1965). Biochem.J. 96, 595.

Barclay, G. R., Flewett, T. H., Keller, E., Halsall, H. B. \& Spragg, S. P. (1969). Biochem. J. 111, 353.

Barker, S. A. \& Whitehead, P. H. (1963). Clin. chim. Acta, 8, 848 .

Bradley, D. E. (1965). J. gen. Microbiol. 38, 395.

Fazekas de St Groth, S. \& Gottschalk, A. (1963). Biochim. biophys. Acta, 78, 248.

Flewett, T. H. \& Apostolov, K. (1967). J.gen. Virol. 1, 297. Hjertén, S. (1964). Biochim. biophys. Acta, 79, 393.

Johnston, J. P. \& Ogston, A. G. (1946). Trans. Faraday Soc. 42, 789.

Lobodzinska, M., Morawiecki, A., Zielinska, J. \& Skurska, Z. (1966). Arch. Immunol. Ter. dośw. 14, 454. 
Morawiecki, A. \& Lisowska, E. (1965). Biochem. biophys. Res. Commun. 18, 606.

Popence, E. A. \& Drew, R. M. (1957). J. biol. Chem. 228, 673.

Schmid, K. (1953). J. Amer. chem. Soc. 75, 60.

Schmid, K. \& Kamiyama, S. (1963). Biochemistry, 2, 271.

Schultze, H. E., Gollner, I., Heide, K., Schonenberger, M. \& Schwick, G. (1955). Z. Naturf. 10b, 463.

Smith, E. L., Brown, D. M., Weimer, H. E. \& Winzler, R. J. (1950). J. biol. Chem. 185, 659.

Tanford, C., Kawahara, K. \& Lapanje, S. (1966). J. biol. Chem. 241, 1921.
Tyrrell, D. A. J. (1954). J. Immunol. 72, 494.

Valentine, R. C. \& Horne, R. W. (1962). In The Interpretation of Ultrastructures, pp. 263-278. Ed. by Harris, R. J. C. New York and London: Academic Press Inc.

Warren, L. (1959). J. biol. Chem. 234, 1971.

Weimer, H. E., Mehl, J. W. \& Winzler, R. J. (1950). J. biol. Chem. 185, 561 .

Whitehead, P. H. (1965). Biochem. J. 85, 8 P.

Whitehead, P. H., Flewett, T. H., Foster, J. H. \& Sammons, H. G. (1965). Nature, Lond., 207, 915.

Whitehead, P. H. \& Winzler, R. J. (1968). Arch. Biochem. Biophys. 126, 657. 